\title{
1989, O ANO QUE NÃO TERMINOU: EPISTEMOLOGIA E METODOLOGIA DA PESQUISA em Comunicação e Política no Brasil
}

\author{
Francisco Paulo Jamil Marques \& Edna Miola
}

\begin{abstract}
Resumo
Este trabalho examina o perfil de parte relevante da produção científica da área de Comunicação e Política no Brasil a fim de elaborar um balanço acerca dos avanços e dos entraves epistemológicos e metodológicos comuns às abordagens investigativas mais recorrentes no país. $\mathrm{O}$ argumento está dividido em quatro partes. Na primeira delas, discutem-se problemas de fundo teórico, apontando-se desde a imprecisão na definição dos objetos até certa desatualização conceitual. Em seguida, a proposta se debruça sobre as falhas que caracterizam algumas das opções metodológicas mais empregadas em pesquisas da área. A terceira seção avalia as consequências dos estorvos anteriormente verificados, mencionando-se, por exemplo, a tendência a elaborar generalizações equivocadas sobre os efeitos políticos da mídia. O texto é encerrado com um tópico disposto a endereçar sugestões que podem colaborar na resolução de parte dos problemas aqui tratados.
\end{abstract}

Patavras-chave

Comunicação; epistemologia; metodologia; política

\begin{abstract}
This paper examines a relevant part of the Brazilian scientific production in Political Communication in order to assess the epistemological and methodological advances and flaws that have featured this area of expertise. The argument is divided into four parts. In the first one, we discuss different theoretical questions, ranging from the imprecision in the definition of objects and categories of research to a persistent conceptual outdatedness. Next, the text focuses on some of the most common methodological options found in empirical studies present in the field, diagnosing the predominance of a descriptive emphasis. The third section reflects on the consequences of the burdens previously pointed out: for example, research findings that tend to overestimate media effects. We conclude our argument by addressing some suggestions that may help to solve part of the problems here outlined.
\end{abstract}

KeYwORDS

Communication; epistemology; methodology; politics

\section{INTRODUÇÃO}

O objetivo deste artigo é examinar o perfil de parte relevante da produção científica da área de Comunicação e Política no Brasil, a fim de elaborar um balanço dos avanços e dos entraves epistemológicos e metodológicos comuns às abordagens investigativas 
mais recorrentes no país. Argumenta-se que um mapeamento das principais ênfases dos estudos elaborados após as eleições presidenciais de 1989 se faz necessário para que seja possível perceber os desafios metodológicos e epistemológicos que marcam a área de Comunicação e Política no panorama brasileiro.

Indo direto ao ponto, pretende-se verificar a impressão de que os avanços na seara teórico-metodológica do referido campo de investigações se mostram relativamente tímidos. Quase 30 anos depois do pleito que levou Fernando Collor à Presidência da República, alguns dos trabalhos mais recentes continuam, por exemplo, a analisar a cobertura eleitoral jornalística praticamente com a mesma visada que caracterizou as pesquisas dos anos 1990.

Ressalte-se que o ano de 1989 é particularmente relevante para a democracia brasileira e para os estudos na área de Comunicação e Política uma vez que, antes daquela oportunidade, as últimas eleições presidenciais no país haviam sido realizadas em 1960. Durante esse intervalo, verificou-se um significativo avanço tecnológico das comunicações no Brasil (com o aprimoramento das transmissões via satélite que tornou as mídias capazes de alcançarem mesmo as regiões mais distantes dos grandes centros), o que encetou novas formas de sociabilidade político-eleitoral. Assim, a redemocratização trouxe a necessidade de que os 22 candidatos que concorreram à Presidência naquele ano tivessem de se adaptar às novas gramáticas audiovisuais, aos debates eleitorais, aos resultados das sondagens de opinião pública e às negociações com os consultores de marketing (Albuquerque, 1999; Carvalho, 1999). Somando-se esses fatores à exibição de uma versão editada do debate presidencial entre Lula e Collor por parte da Rede Globo (2018), catalisou-se a onda de estudos que iria conferir relevância à área de Comunicação e Política no Brasil (Weber, 1990). A partir daquele ano, ficou mais evidente uma nova frente de investigações, disposta a não mais examinar a Comunicação somente como política de Governo - perspectiva predominante até então por conta da regulamentação e da censura impostas pelo Regime Militar (Lima, 1997).

Mesmo que aquela eleição tenha acontecido há quase três décadas, a impressão de que os avanços na pesquisa se mostram limitados se espraia para diferentes subespecialidades ou temas associados ao campo de investigações em questão. Se, a título de ilustração, tomarmos os estudos sobre Jornalismo Político no Brasil, perceber-se-á que uma série de leituras continua a tratar agentes e fenômenos como se o cenário político-midiático fosse praticamente o mesmo desde a eleição de Collor, em 1989. Evidências diversas - como a de que as organizações Globo não têm o mesmo poder de influência anteriormente verificado (Sampaio, 2010), dada alteração nos modos de consumo de informações políticas; a exemplo da mudança de postura do referido grupo midiático quanto a algumas dimensões da cobertura eleitoral (Rede Globo, 2018); ou da competição do Jornalismo com as redes sociais digitais (Canavilhas, 2010) - apontam que a atividade noticiosa se transformou desde então (Guerra, 2014). Além dela, as gramáticas e as formas de se conduzir uma campanha eleitoral também se modificaram (Gomes, 2004); já do ponto de vista institucional, o Estado brasileiro se encontra em contínua modificação (Bresser-Pereira, 2017). Uma parcela da produção científica, contudo, 
permanece atrelada a um referencial que carece de atualização teórica, metodológica e epistemológica. É o que se propõe discutir aqui.

Antes de prosseguir com o argumento, elabora-se algumas notas de cautela. Cabe, primeiramente, admitir que este é um diagnóstico incompleto. Mesmo que esta proposta não tenha caráter experimental-quantitativo, e sim reflexivo, o texto precisa enfrentar a acusação de que conta com limitações ao não revisar integralmente o que foi produzido até o momento - aliás, essa seria uma tarefa impossível, dado que o fluxo da produção científica é perene. Justamente por isso, evita-se generalizar o diagnóstico.

Contudo, mesmo sem estabelecer um corpus precisamente delimitado, é possível esclarecer que tipo de produção científica foi levada em conta pelos autores deste artigo. Dito de forma mais clara, são quatro as fontes principais que permitiram ao texto compilar as tendências de investigação em Comunicação e Política no Brasil. A primeira delas se refere às atas do Grupo de Trabalho (GT) Comunicação e Política da Associação Nacional dos Programas de Pós-Graduação em Comunicação e Política, que existe desde 1992. O grupo debate, anualmente, 10 trabalhos, acumulando, até o momento, mais de 250 artigos (Compós, 2018). Pesquisadores de diferentes instituições de pesquisa - muitos deles veteranos que já formaram investigadores de gerações mais recentes - coordenaram o referido espaço de debates, que funciona como caixa de ressonância a agregar comunicólogos, cientistas políticos e outros estudiosos com produção relevante.

A segunda fonte abrange os trabalhos apresentados nos GTs da Associação Nacional dos Programas de Pós-Graduação em Ciências Sociais. O evento anual desta entidade ofereceu uma de suas primeiras oportunidades à Comunicação e Política em 1994, em uma sessão intitulada "Mídia e Cidadania" do GT Cultura e Política. Em 1996, foi a vez de o GT Partidos Políticos e Comportamento Eleitoral dar visibilidade ao assunto, por meio da sessão "Mídia, Socialização Política e Descrença Política". Foi somente em 1997, porém, que a ANPOCS começou a reservar espaço cativo aos autores vinculados ao tema, ainda que o nome do GT tenha sofrido variações. A título de ilustração, o grupo se intitulava "Mídia, Política e Opinião Pública" quando de sua estreia; "Mídia, Opinião Pública e Eleições", em 2000; “Democracia, Comunicação Política e Eleições”, em 2004; "Democracia, comunicação política e eleições", em 2009; "Mídias, política e eleições", em 2008 (ANPOCS, 2018).

A terceira base a possibilitar um panorama da especialidade é o Diretório de Teses e Dissertação da Associação Brasileira de Pesquisadores em Comunicação e Política, cujo catálogo conta com cerca de 500 títulos (Compolítica, 2018). O repositório se encontra dividido em nove temáticas (de Propaganda e Marketing Político a Jornalismo Político, entre outras) e permite conhecer instituições, pesquisadores e indicadores de produção - itens que foram objeto de artigos já publicados, a exemplo de Aldé, Chagas \& Santos (2013) e Santos, Aldé \& Schwambach (2016).

Por último, é possível indicar um conjunto de coletâneas que marcam as tendências da produção científica brasileira na especialidade aqui examinada - sobretudo porque, uma vez mais, envolvem pesquisadores que ainda detêm posição de liderança na área. A título de ilustração, pode-se mencionar o livro Mídia, Eleições e Democracia, organizado por Heloiza Matos em 1994; o livro Comunicação e Política: Conceitos e Abordagens, 
publicado sob responsabilidade de Albino Rubim em 2004 e resenhado por João Carlos Correia (2005) como representativo da produção nacional; e Mídia, representação e democracia, organizado por Luis Felipe Miguel e Flávia Biroli, em 2010.

Ainda que tais fontes não sejam abordadas empiricamente; ainda que o conhecimento que delas se tem não permita a generalização das conclusões para todo o campo de estudos; e mesmo que consideremos legítimas estas e outras ressalvas ao trabalho ora apresentado, defende-se a utilidade deste artigo por provocar o debate e por trazer à tona considerações sobre os progressos e os entraves que dificultam, por exemplo, a ampliação do grau de impacto internacional de publicações brasileiras em nível internacional. Este, aliás, constitui um dos maiores estorvos apontados pelo Relatório da Avaliação Quadrienal 2017 da área de Comunicação e Informação, elaborado sob responsabilidade da CAPES (2017). Assim, sustenta-se a ideia de que, a partir desta contribuição, o leitor terá a oportunidade de identificar (e de evitar) os obstáculos aqui retratados quando da condução de seus próprios projetos em Comunicação e Política.

Esclareça-se, ademais, que, ao contrário da proposta de Alan Sokal e Jean Bricmont (2010), no livro Imposturas intelectuais, a ideia deste artigo não, de forma alguma, é denunciar "abusos" (sic) - ainda que a questão do relativismo epistêmico levantada por esses dois autores represente um foco de inquietação, conforme será explicado em breve. Aliás, sublinhe-se que, em nenhum momento, o propósito do artigo é sinalizar a existência de má-fé por parte dos autores ou dos trabalhos referenciados. Deseja-se, somente, colocar em pauta obstáculos que podem comprometer o acúmulo de conhecimento em nosso campo de estudos. Isto é, a questão de fundo se refere à necessidade de abordar problemas analíticos que, até o momento, não têm sido objeto de reflexão de forma suficiente. Aliás, também de forma oposta ao que fizeram Sokal e Bricmont (2010), optou-se, no escrito ora apresentado, apenas por ilustrar alguns dos trabalhos que se encaixam em situações problemáticas. Isso porque, uma vez mais, não haveria vantagem alguma em gerar mal-entendidos ao se personalizar a crítica quando a meta é explorar elementos que parecem ter alcance mais amplo do que o trabalho de um grupo ou de uma linha desenvolvida em instituição de pesquisa específica.

Defende-se, todavia, que as questões apontadas nesta proposta não constituem exceções, uma vez que se dão em número significante. Evidências disso podem ser testemunhadas a partir de, pelo menos, três fontes: a primeira delas reside em problematizações e fenômenos abordados em coletâneas publicadas nos últimos anos - das quais Rubim (2004), já citado, é um exemplo; a segunda evidência se encontra nos documentos de área que veiculam a avaliação que a CAPES faz da área de Comunicação documentos, aliás, que, por serem referência para as políticas acadêmicas e científicas, são abordados mais adiante neste artigo; por fim, ao longo do presente argumento, dialoga-se com outros pensadores do campo que compartilham das mesmas preocupações aqui diagnosticadas.

O trabalho se encontra dividido em quatro partes. Na primeira delas, discutem-se problemas de fundo teórico, apontando-se desde a imprecisão na definição dos objetos até certa desatualização conceitual. Em seguida, a proposta se debruça sobre as falhas 
que caracterizam algumas das opções metodológicas mais empregadas em trabalhos da área. A terceira seção avalia as consequências dos problemas anteriormente verificados, mencionando-se, por exemplo, a tendência a elaborar generalizações equivocadas sobre os efeitos políticos da mídia. O texto é encerrado com um tópico disposto a endereçar sugestões que podem colaborar na resolução de parte dos problemas aqui tratados.

\section{DifiCUlDADES TEÓRICAS}

\section{DA IMPRECISÃO TERMINOLÓGICA}

A área de Comunicação e Política, por sua história e legado, reúne investigações de naturezas diversas. É possível concentrar os estudos em diferentes momentos da vida política das sociedades (períodos de mandatos, de eleições ou de crises institucionais), enfatizar mensagens veiculadas em determinados suportes (televisão, rádio, material impresso e dispositivos digitais), dar atenção à mobilização midiática de certos atores políticos (representantes eleitos, candidatos, movimentos sociais, consultores de comunicação, jornalistas) ou, de forma mais ampla, dedicar-se a pesquisar as variadas atividades sociais que envolvem a mídia e a democracia (a exemplo da atuação do Estado na regulação do mercado de comunicação) (Albuquerque, 2013; Coelho \& Locatelli, 2017; Gomes \& Maia, 2008; Maia, 2012; Miguel \& Biroli, 2010; Rubim, 2004; Weber, 1990). Assim, a oportunidade de associar plataformas, suportes, agentes e atividades confere aos estudiosos da área a vantagem de ter à mão uma fonte praticamente inesgotável de temas de investigação.

Ao mesmo tempo, tal profusão de opções pode implicar dificuldade em cercar, de maneira mais clara, os objetos de estudo da especialidade aqui abordada. Dito de outra forma, se é preciso ressaltar as vantagens trazidas pela interdisciplinaridade que marca os Estudos de Mídia, não se pode ignorar a preocupação com as imprecisões terminológicas que caracterizam parte de nossas produções. Se for tomada como exemplo a ideia de "esfera pública" (Habermas, 1984), será possível verificar que o movimento dedicado a esgarçar tal conceito a fim de que ele abarque uma pluralidade de fenômenos e ambientes pode acabar provocando sua própria inutilidade (Marques, 2006; Miola, 2009). Situação semelhante ocorre com os conceitos de "poder" ou "espetacularização" (Chaui, 2006; Guareschi, 1994); já a definição de "interesse público" adota perspectivas por vezes conflitantes quando designa experiências de Comunicação Pública (Duarte, 2012; Matos, 2012; Paulino, Guazina \& Oliveira, 2016).

Mas, sublinhe-se, este traço de imprecisão terminológica não é marca apenas da subárea de Comunicação e Política. Conforme Moragas:

a história da investigação sobre comunicação de massas põe de manifesto que as colocações que pretendem constituir este trabalho em uma disciplina "independente", homologável em status às ciências sociais, revelaram-se tarefa muito pouco rentável para o desenvolvimento ou progresso dos conhecimentos sobre nosso objeto de estudo, sempre difícil de delimitar. (1981, p. 12) 
O caso é que, nos estudos brasileiros em Comunicação e Política, mostra-se frequente o uso de macrocategorias que, ao serem empregadas para explicar fenômenos díspares, acabam gerando mais dúvidas do que esclarecimentos. Se "meios de comunicação", "grande mídia" ou "mídia hegemônica" permanecem sendo termos muitas vezes utilizados como sinônimos, registre-se que uma observação mais atenta por parte do leitor revelaria um conjunto de confusões terminológicas.

Dizendo-se de forma mais clara e objetiva, ainda não se conseguiu vencer, por completo, a desordem conceitual que cerca, por exemplo, a noção de "mídia". O termo pode designar dispositivo para armazenamento de dados (Figueiredo \& Mendes, 2015), canal de comunicação através do qual a mensagem é transmitida (Peruzzo, 2003), área de atuação no agenciamento de propaganda (Giacomini Filho, 2013) ou agentes ligados ao campo do Jornalismo (Fernandes \& Correia, 2014). O uso indiscriminado do termo "mídia", assim, deixa em segundo plano toda a riqueza de fenômenos, serviços, interesses, mercados, profissionais, deontologias, tecnologias, técnicas e práticas que marcam a comunicação de massa contemporânea (Citelli, Berger, Baccega, Lopes \& França, 2014). Quando as análises pecam quanto à cautela conceitual e insistem em tratar com a mesma lente investigativa (sob o guarda-chuva "mídia") atividades diversas, torna-se frequente o embaralhar entre meios (em uma perspectiva instrumental-propagandística), de um lado, e instituições, de outro. Se, em princípio, fosse admitido que tais distinções poderiam estar claramente estabelecidas na mente dos autores, talvez seja necessário padronizar uma melhor a dimensão redacional (Fausto Neto, 2004).

\section{DESATUALIZAÇÃo DA LITERATURA}

Mostra-se comum, em trabalhos brasileiros da área de Comunicação e Política, a utilização de referenciais clássicos das Teorias da Comunicação. Em princípio, isso não seria problema, mas é preciso reconhecer que, em situações diversas, teorias e hipóteses da década de 1970 ainda são apresentadas como se novidade fossem.

Observe-se, a título de ilustração, mesmo o caso daqueles estudos mais recentes sobre agendamento midiático (Gomes \& Torres, 2017). Se, por um lado, é possível argumentar que novos canais de comunicação encetam possibilidades inéditas quanto ao processo de agendamento (é o caso dos fluxos que envolvem redes sociais digitais), por outro lado, as perguntas de partida e as providências empíricas continuam, muitas vezes, limitadas a reproduzir o que já se faz há décadas (McCombs \& Shaw, 1972).

Para não ser injusto, é prudente ressaltar que um grupo de investigações, na última década, passou a considerar o conceito de framing (também conhecido como "segundo nível de agenda-setting") (Liedtke, 2008) - ainda que quase sempre reproduzindo o que desenvolveram, sob diferentes olhares, Gamson e Modigliani (1989), Entman (1994) ou Goffman (1986), que tampouco são referências recentes.

$\mathrm{Na}$ prática, o que diferentes textos dedicados a analisar enquadramentos fazem é adotar a seguinte lógica: introduzir ao leitor o esforço metodológico elaborado em um dos trabalhos de autores pioneiros; modelar os critérios de análise lançando mão 
de categorias que, muitas vezes, sobrepõem-se ou procedem a uma classificação dos quadros de maneira marcadamente subjetiva e de sistematização que dá excessivo espaço a polêmicas. Nesse sentido, sob a justificativa de que "cada caso é um caso", fica estabelecida uma zona de conforto teórico-metodológico que mantém sintonia com o que foi explorado décadas atrás, como se pouco tivesse sido aperfeiçoado desde então. Exceções podem ser encontradas em Vimieiro e Maia (2011) e em Campos (2014), que adotam uma postura interessante quanto às aplicações conceituais clássicas e que montam uma arquitetura empírica original.

\section{DifiCUlDADES METODOLÓGICAS}

Falava-se, no início dos anos 2000, que a área de Comunicação no Brasil se caracterizava pela dificuldade em acumular conhecimento, dadas as fragilidades das pesquisas anteriores. Quem desejava descobrir algo, teria de partir praticamente do zero por conta da inconsistência metodológica da maioria dos estudos até então elaborados. De acordo com o então representante de área de Ciências Sociais Aplicadas I no Ministério da Educação:

falta à mentalidade dos programas [de pós-graduação em Comunicação], em geral, uma ideia clara e efetiva de pesquisa cumulativa. Ou se desconhece o trabalho anterior ou ele é de tal forma pouco confiável em seus resultados que os nossos pesquisadores estão sempre começando de novo o trabaIho da produção de conhecimento sobre um tema ou especialidade. Desse modo é praticamente impossível estabilizar um campo de pesquisa com um volume suficiente de conhecimento consolidado, isto é, testado, avaliado e aceito pela comunidade de pesquisa. (Gomes \& Moreira, 2000, p.131)

Em se tratando, especificamente, dos estudos em Comunicação e Política, o aumento numérico de pesquisadores, bem como a citação mútua de trabalhos da área, não implicou, necessariamente, avanço notável em termos metodológicos a ponto de nos inserir nos embates travados internacionalmente em periódicos de ponta (não obstante o esforço relevante verificado em congressos da área). É o que se debate a seguir.

\section{POUCO SE CRIA E MAL SE COPIA}

A Comunicação é uma área do conhecimento que, no caso brasileiro, consolidou-se a partir da segunda metade do século XX, fenômeno que se deve a elementos tais como a ampliação no número de cursos de graduação e pós-graduação no país (Melo, 1999). Sabidamente, o ato de reivindicar objetos, teorias e problemas de investigação próprios requer, também, o desenvolvimento de metodologias de pesquisa singulares (Silva, 2009). Isso não significa, naturalmente, a defesa de um isolamento no que se refere à proposição ou ao emprego de técnicas de investigação.

Sendo assim, argumenta-se que, se, por um lado, o diálogo com métodos de análise oriundos de outras áreas do conhecimento é fundamental, por outro, demanda-se 
um profundo domínio de tais técnicas - seja para reproduzi-las, seja para adaptá-las. No caso, não se pode negar que o processo de apropriação implica adaptações nem sempre felizes.

Vejamos o caso da utilização da análise de conteúdo (ou a adoção de parâmetros da análise de discurso, ambas em suas mais variadas vertentes), que, muitas vezes, desconsidera particularidades das áreas que originaram tais estratégias. Por exemplo, utilizar AD em conjunção com AC para tratar um mesmo corpus é alvo de crítica em variadas referências fundamentais (Bardin, 2007; Charaudeau, 2006; Fairclough, 2001; Foucault, 1979; Orlandi, 2007; Pêcheux, 1988; Van Dijk, 2008).

Outro exemplo da transposição de técnicas de análise encontra-se em trabalhos brasileiros direcionados a investigar a ideia de deliberação pública (Seridorio \& Luvizotto, 2017). Embora os modelos teóricos inspiradores de tal perspectiva (Bohman, 1996; Elster, 1998; Gutmann \& Thompson, 1996; Habermas, 1996) sejam frequentemente criticados por conta de seu caráter normativo, não são poucas as pesquisas nacionais que, de antemão, optam por selecionar um conjunto específico de parâmetros (reflexividade, representatividade, reciprocidade, dentre outros) cuja resultante é a frustração com as descobertas da investigação (lamenta-se, por exemplo, que, não obstante o potencial discursivo de fóruns online, os cidadãos insistem em se atacar ou se manter em silêncio). Isso ocorre não somente porque a realidade se mostra ao pesquisador como sendo diferente daquilo que por ele foi desenhado como ideal, mas, também, pela necessidade de se considerar a influência dos contextos socioculturais e de momentos políticos determinados sobre os processos de conversação política - em um debate eleitoral televisivo, por exemplo, convergir com o oponente pode aumentar as chances de perder votos (Marques, Vimieiro, Vieira \& Melo, 2009). Nesse sentido, parte dessas investigações (Sousa \& Marques, 2015, por exemplo) aponta contribuições que se limitam a ilustrar (a) que cada caso é um caso, (b) que dificilmente se verifica debate público de boa qualidade (sobretudo em contextos acirrados) e (c) que os modelos analíticos elaborados pecam ao tentar fazer a realidade da dinâmica deliberativa caber em categorias elaboradas no plano teórico-filosófico.

\section{MuITA DESCRIÇÃo, POUCO AVANÇO HEURístico}

A consistência de um estudo empírico se revela nas dimensões concernentes à adequação dos métodos de coleta, dos métodos de análise e à profundidade da interpretação dos resultados - que deve se dar em confronto direto com a literatura pertinente.

Enquanto a informatização dos bancos de dados e a utilização de softwares e aplicativos têm proporcionado avanços notáveis em métodos de coleta, o progresso no que se refere às formas de interpretação do material extraído, contudo, ainda parece acanhado. São diversas as propostas na área de Comunicação e Política no Brasil que, no âmbito dos eventos relacionados às tecnologias da comunicação em rede, por exemplo, satisfazem-se em contar número de hashtags, posts ou seguidores.

Em outras palavras, se as ferramentas de coleta de metadados podem contribuir para ampliar as possibilidades de análise empírica, permitindo o processamento de 
dados ou o estabelecimento de associações até então mais trabalhosas por serem executadas manualmente, isso não significa que as pesquisas tragam conclusões que façam avançar a compreensão que se tem do estado da arte. É o caso das aparentemente sofisticadas análises de redes que, ao lançarem mão de grafos ou ao se debruçarem sobre relações entre "influenciadores" e "influenciados", pouco se preocupam em refletir, por exemplo, acerca dos reais efeitos das formas de uso das mídias digitais sobre as decisões políticas. Ao dizer isso, este ensaio não visa desvalorizar as informações levantadas nas referidas investigações; o problema se refere, antes, à impressão de que boa parcela dos estudos a dominarem tais recursos poderia empregar os dados coletados de forma mais produtiva, de forma a estabelecer um confronto que vá além das ilustrações (Recuero, Zago \& Bastos, 2014).

Há, também, trabalhos nos quais o esforço para montar uma metodologia de pesquisa robusta resulta em um tipo de argumento que privilegia o método em si (a arquitetura da coleta, por exemplo), em detrimento do próprio problema investigado. Uma vez mais, a intenção aqui não é depreciar o fato de que, em determinadas ocasiões, as descrições são necessárias como sendo o primeiro passo no sentido de realizar um mapeamento que permitirá, em etapas posteriores, descobertas mais consistentes. A questão é: a partir de qual momento consideramos ser suficiente tal inventário de fenômenos, a fim de não repetirmos ad infinitum ilustrações de casos que, muitas vezes, pouco ajudam a ampliar nossa compreensão acerca dos objetos analisados?

\section{FALHAS NO PROCESSO DE MONTAGEM E DE APLICAÇÃO DAS ESTRATÉGIAS METODOLÓGICAS}

Ainda vinculada à discussão metodológica, uma polêmica recorrente nos estudos em Comunicação e Política no Brasil (algo que, na verdade, permeia as Ciências Humanas e Sociais) se refere à disputa entre pesquisadores que enfatizam métodos quantitativos ou qualitativos. Se a pesquisa na área evoluiu a ponto de perceber que as duas abordagens não são antagônicas (Cervi, 2009), o esforço mais recente tem sido ratificar a ideia de que determinadas perguntas de partida apenas são passíveis de resposta caso o leque de técnicas selecionado para conduzir o estudo seja condizente com o problema de pesquisa. Tomemos o caso de uma investigação acerca das tensões que marcam os bastidores da interação entre as coordenações de política, de um lado, e de marketing, de outro, que prestam serviço a determinada candidatura (Marques \& Carneiro, 2018). No caso, as entrevistas em profundidade seriam uma das poucas alternativas capazes de dar resposta a tais inquietações - e de pouco adiantaria a insistência na utilização de métodos quantitativos se apenas a interlocução direta com agentes envolvidos no processo em questão pode ajudar a revelar as atitudes e as perspectivas dos participantes (Barakso, Sabet \& Schaffner, 2014). Nessas ocasiões, o rigor metodológico deve se referir a questões sobre como garantir a representatividade dos entrevistados e a transparência dos dados primários (tornar disponíveis as transcrições das entrevistas, por exemplo).

Verifica-se, ademais, a existência de pesquisas que reivindicam caráter quantitativo (dispostas, para isso, a apresentar tabelas e gráficos das mais diversas naturezas e 
formatos), mas que, no final das contas, limitam-se a contar frequências (indicar quantas vezes determinados termos aparecem na amostra, por exemplo) (Grijó \& Vieira, 2017). A crítica se volta, assim, para aqueles casos que apenas enfatizam a descrição dos dados coletados, tendo sua contribuição limitada a ilustrar o que ocorreu em uma situação particular (Andrade, 2014).

Uma análise quantitativa consistente parte de distinções entre variáveis dependentes e independentes, sendo capaz de avaliar possíveis correlações entre estas; reflete acerca da pertinência dos índices a serem averiguados e cotejados; separa as variáveis mais relevantes para a explicação de determinado problema, evitando regressões espúrias ou atribuindo pesos a fatores essencialmente diferentes; especula acerca do grau de influência mútua entre as variáveis, para evitar duplicação ao mensurar os efeitos. Nem sempre tais aspectos são contemplados nas investigações de nossa especialidade.

Analisemos o caso de estudos que se autointitulam "quantitativos" ao lançarem mão de categorias (sejam elas fundamentadas na literatura, sejam elas construídas indutivamente) dispostas a avaliar, por exemplo, o conteúdo de materiais da comunicação política. Em diferentes trabalhos (Marques, Silva \& Matos, 2012), percebe-se que não há preocupação evidente em construir os índices considerando-se a maior (ou menor) proximidade (ou até sobreposição) das tipologias entre si. O resultado, às vezes, refere-se a taxonomias nas quais se confunde forma, função e conteúdo de agentes, agendas e propostas - sem contar o inchaço da categoria "outros", que focaliza situações não contempladas nos indicadores inicialmente propostos.

Ressalte-se, a esta altura, que há providências metodológicas que não dependem do desenvolvimento de novas técnicas ou que se encontram além dos cuidados a serem tomados quando do processo de montagem dos indicadores analíticos. Aqui se está fazendo menção, novamente, à importância de ser transparente quanto ao uso das técnicas de coleta, análise e interpretação dos dados: como foi feita a classificação do conteúdo? Quantos pesquisadores tomaram parte no processo? Houve treinamento da equipe responsável pela catalogação e classificação? Foi realizado teste de confiabilidade? 0 que foi feito no caso de divergência entre os investigadores ao longo do processo de categorização? Se a classificação ficou por conta apenas de um investigador, quais os riscos de uma análise eminentemente subjetiva comprometer os resultados apresentados?

A tais respostas devem ser acrescidas a disponibilização do banco de dados e do livro de códigos utilizado para a categorização, o que permitiria replicar os procedimentos, bem como checar possíveis inconsistências. Nesse sentido, este trabalho chama a atenção para um fato apontado por Gary King (2006) há mais de uma década: periódicos diversos (inclusive da área de Ciências Humanas e Sociais) têm adotado políticas de compartilhamento de dados brutos e investido em normas que encorajam os leitores a replicar os resultados dos trabalhos que veiculam. Em resumo, não apenas os trabalhos da área de Comunicação e Política, mas, também, qualquer trabalho científico deve evitar que o leitor ou avaliador tenha de confiar na palavra do pesquisador. 


\section{CONSEQUÊNCIAS DOS PROBLEMAS TEÓRICO-METODOLÓGICOS}

As dificuldades teóricas e metodológicas de parte dos trabalhos abrigados na interface entre Comunicação e Política no Brasil podem ser verificadas em suas respectivas conclusões. Pelo menos três problemas se destacam nos resultados de diferentes pesquisas sobre a mídia e a democracia: certo exagero quanto aos efeitos da comunicação de massa sobre a audiência; a generalização dos achados (descobertas sobre casos específicos nem sempre se aplicam a um corpus mais abrangente); e uma espécie de síndrome da perseguição ideológica, alinhada com a ideia de "percepção de mídia hostil" (Vallone, Ross \& Lepper, 1985).

\section{A QUESTÃo DO HIPERMIDIATISMO E DA GENERALIZAÇÃO DAS CONCLUSÕES}

A boa qualidade de uma investigação empírica é aferida por meio da literatura atualizada e plural que o trabalho aciona, bem como através dos parâmetros empíricos utilizados para dar conta de determinado fenômeno, objeto ou corpus. Além disso, a discussão proporcionada após a apresentação dos dados também se mostra fundamental para convencer o leitor de que as descobertas da análise são convincentes. É nesse ponto que um entrave adicional se mostra perceptível na especialidade ora examinada.

Em diferentes ocasiões, o estudo acerca da utilização de uma plataforma de comunicação específica (ou a abordagem empírica sobre um ator ou instituição em particular) acaba servindo para fazer ilações de cunho mais amplo. Esse fenômeno é mais facilmente verificável em trabalhos dedicados à comunicação eleitoral. Persistem análises orientadas estritamente de acordo com o resultado do pleito. Por exemplo: se determinado candidato foi derrotado, isso se deveria a uma utilização equivocada das estratégias de comunicação - não importa se a margem de derrota foi mínima e nem se existem outros fatores associados ao contexto, à agenda da campanha ou ao comportamento do eleitor, conforme bem apontam Figueiredo (2008) e Moisés (2008).

A depender do caso, o estudo de um simples perfil do Instagram é o objeto utilizado para identificar o tom geral de uma campanha ou mesmo para explicar o motivo pelo qual a eleição foi (ou não) um sucesso para determinado candidato. Aponta-se, então, para a necessidade de se evitar uma perspectiva "hipermidiática", uma vez que nem tudo do ponto de vista eleitoral se resume à construção de imagem; nem sempre microfenômenos são suficientes para explicar vitórias e derrotas na disputa pelo voto. É nesse sentido que se mostra fundamental adotar uma postura que reconheça as limitações das próprias descobertas - o que nem sempre ocorre.

\section{A SÍNDROME DA PERSEGUIÇÃo IDEOLÓGICA}

É necessário discutir se, e em que medida, verifica-se alguma influência ideológico-partidária em análises da área de Comunicação e Política no Brasil. Registre-se, antes de dar continuidade ao presente tópico, que não se trata de crítica às pessoas dos autores ou às preferências partidárias que, por acaso, eles possam, legitimamente, ter. O que 
se apela é para que seja ampliado o esforço em evitar uma possível interpretação dos fenômenos que se confunda a defesa de determinada diretriz política.

De forma prática, é preciso dizer que não se verifica novidade alguma em afirmar (ou mesmo denunciar, a depender do ânimo) que empresa de comunicação " $x$ " tem preferência editorial por uma agremiação ou tendência política particular. Há, inclusive, casos em que as instituições jornalísticas apoiaram, de maneira aberta, determinadas candidaturas, conforme ocorreu com a Folha de S. Paulo em 2000, quando endossou Marta Suplicy (Partido dos Trabalhadores) na disputa para a Prefeitura de São Paulo (Marta X Maluf, 2000, 15 de outubro, p. A2); ou o caso do jornal O Estado de S. Paulo, que optou por José Serra nas eleições presidenciais de 2010 (Editorial: O mal a evitar, 2010, 26 de setembro, p. $A_{3}$ ).

Além dessas ocasiões, há distinções importantes de serem feitas quando tratamos, por exemplo, de diferentes gêneros jornalísticos: (a) a postura de um ou outro articulista contrário a determinado partido pode ser clara e textual, até porque alguns deles já eram, de origem, filiados a movimentos políticos ou sociais antes de serem convidados a escrever; (b) há circunstâncias em que a audiência talvez não compreenda, por completo, as separações entre notícia e opinião. Mas o que se vê, com alguma regularidade, são trabalhos acadêmicos que encontram obstáculos mesmo para diferenciar, de um lado, a abordagem noticiosa e, de outro, a postura editorial do jornal.

Com isso, não se está afirmando que o proprietário ou que os acionistas majoritários da empresa não busquem direcionar a agenda da cobertura cotidiana; que não exista sincronia e sintonia entre agendas noticiosas e editoriais (Marques, Miola, Mitozo \& Mont'Alverne, 2017); nem se está negando que os próprios jornalistas também podem preferir dar voz a fontes que ideologicamente consideram mais apropriadas; e, por último, não se está diminuindo a influência política dos jornais sobre a audiência (Eilders, 1999; McKnight, 2010). O argumento, aqui, é mais simples: boa parte da crítica acerca do desempenho ou do viés adotado pelas mídias jornalísticas (Chaui, 2006) se trata mais de premissa do que de conclusão empiricamente comprovada.

Mais frequentemente presumido do que testado (ou seja, uma narrativa, não ciência), os efeitos negativos da mídia alcançaram o status de mito nacional no país que produziu tanto o verdadeiro William Randolph Hearst ("Você fornece as imagens, eu forneço a guerra": 1897) quanto sua apoteose fictícia (As pessoas pensarão... o que eu lhes disser para pensar": 1941). (Hartley, 2015, p. 852)

Essas constatações não pretendem invalidar os esforços feitos no sentido de identificar interesses "fora de cena" (Gomes 2004). O argumento deste trabalho, na verdade, mantém sintonia com Luis Felipe Miguel, quando o autor se debruça sobre pesquisas fundamentadas na técnica de análise de valências:

não creio que se trate de, junto com a ferramenta da valência, invalidar a ideia de que existe viés no noticiário, atribuindo tudo à dissonância 
cognitiva dos consumidores de informação (Gomes, 2014). O caminho é, exatamente, avançar numa compreensão mais complexa, impedindo que as debilidades do recurso à valência comprometam nossa capacidade de fazer uma crítica embasada da ação política da mídia. (Miguel, 2015, p. 175)

A referida "compreensão mais complexa" se refere, provavelmente, à importância de se admitir que existem lógicas próprias de produção no Jornalismo, dinâmicas que nem sempre estão meramente circunscritas à ação política; ou que se considere a existência da ação política do Jornalismo sem equipará-lo a partidos políticos, como bem aponta Biroli (2013).

Aliás, Azevedo (2010) compartilha avaliação semelhante ao apontar a necessidade de produzir explicações mais substantivas para que seja possível medir o grau de partidarismo no caso do Jornalismo brasileiro:

respeitando-se a legítima opção democrática de cada veículo da imprensa optar por uma das candidaturas em competição, a questão a ser respondida é se o PT e o seu candidato presidencial desde 1989 (Lula) receberam um tratamento equilibrado e em pé de igualdade com seus principais adversários políticos. (...) Caso a resposta seja negativa, é necessário produzir uma explicação consistente que vá além da teoria conspiratória das "classes dominantes" contra o PT ou da simples constatação de que o DNA da mídia é conservador e ponto final. (Azevedo, 2010, p. 50)

Assim, se a influência da direção da empresa não pode ser descartada (ainda que poucos trabalhos tenham mensurado de forma confiável como tal processo ocorre), continua fundamental compreender em que medida a instituição negocia com o fato de que há princípios, competências e habilidades fomentadas durante a trajetória de formação dos profissionais e que também sustentam o contrato de leitura das empresas jornalísticas com suas audiências (Fausto Neto, 2008). Não se pode, enfim, ignorar as peculiaridades da rotina de tal atividade ou o esforço analítico de pesquisadores das Teorias do Jornalismo.

De forma mais direta, pergunta-se: as notícias, de fato, posicionam-se de maneira tão clara, conforme constatam textos dedicados a denunciar o viés da cobertura? É possível asseverar que o grau de luminosidade de uma fotografia teve como intenção ressaltar a presença de determinada figura política? Que o ângulo escolhido pelo fotógrafo produzirá os mesmos sentidos junto à audiência? Não parece adequado, então, presumir - sem o devido tratamento empírico - quais seriam as intenções dos produtores das mensagens; assim como também é desaconselhável generalizar os efeitos dos produtos midiáticos sobre diferentes parcelas do público, conforme pondera o importante estudo elaborado por Mundim (2014).

É legítimo questionar, a esta altura, se existe o risco de os trabalhos elaborados não enxergarem seu próprio viés. Tal postura, aliás, também é criticada mesmo por autores com atuação político-partidária, conforme aponta o trecho abaixo: 
Florestan Fernandes, quando discute 'sobre o trabalho teórico', observa que 'uma atividade militante intensa é incompatível com a vida acadêmica: ela pode ser posta de modo transitório em dados momentos'. A política quebra o isolamento intelectual, mas seu exercício prolongado nos empurra para as razões pragmáticas que lhes são inerentes. (Ortiz, 1990, p. 173)

Nesse cenário, torna-se comum que resultados de investigações no campo da Comunicação e Política sejam utilizados por agremiações partidárias a fim de ratificar uma visão de mundo a ser compartilhada pela militância (Partido dos Trabalhadores, 2015).

Para encerrar o tópico, é possível apontar outro prejuízo analítico caso se confirme ou se exacerbe o risco ora discutido: a circulação regular e comumente aceita de diagnósticos "certeiros" sobre os efeitos políticos das mídias nos induz à sensação de que estes estariam dispensados de maior rigor avaliativo (justamente por trazerem embutidas perspectivas de mundo amplamente compartilhadas e convenientes). Trata-se de problema relevante, sobretudo caso seja verificada resistência em se aceitar, quando dos processos de avaliação de artigos e projetos, o estudo de agendas ou instituições que são tidas como "conservadoras". Seria nocivo para o ambiente de pesquisa cercear estudos que contemplem entidades tidas como "inimigas" por uma parcela do campo.

\section{PARA CONCLUIR: PERSPECTIVAS DE MELHORIA}

O livro Opinião Pública, de Walter Lippmann (1922/2008), é considerado, por diferentes estudiosos, como um dos precursores dos estudos em Comunicação e Política. Desde os primórdios da especialidade aqui abordada, os investigadores a ela vinculados procuraram se posicionar de forma preponderantemente "crítica" ao desempenho político da comunicação de massa. Seja em relação aos papeis dos profissionais e das empresas jornalísticas, seja no que concerne à dinâmica de trabalho dos spin doctors e demais agentes dedicados à construção de imagens públicas, o fato é que as ressalvas reverberam, hoje em dia, não mais apenas entre os estudiosos da Comunicação Política, mas é, também, oriunda de não especialistas.

Há algo de positivo nisso: uma maior parcela dos cidadãos passa a acompanhar mais de perto os produtos e os agentes da política midiática, restando-se mais atentos à cobertura jornalística, ao padrão dos programas eleitorais e ao desempenho dos candidatos ao longo dos debates. Mas não se deve deixar de perceber, por outro lado, que tal disposição em avaliar continuamente (e, muitas vezes, sem conhecer os parâmetros de funcionamento do campo) o desempenho do sistema midiático parece evidenciar, em parte, a necessidade de que os estudos em Comunicação Política no Brasil se firmem como autoridade de referência.

Em tempo: não se está sugerindo que o campo deva se fechar a avaliações externas, nem se está censurando a apresentação de ressalvas por parte de não-especialistas. $O$ que se está sugerindo é a necessidade de que a literatura pare de andar em círculos. Mesmo cerca de 30 anos depois da redemocratização brasileira, permanece-se com muitas das perguntas de partida originalmente formuladas, perscrutadas por meio de estratégias metodológicas repetitivas, o que dificulta a consolidação da autoridade da disciplina. 
Com vistas a encerrar o ensaio ora apresentado, a intenção é abordar, a seguir, duas questões adicionais, intimamente ligadas, que funcionam como sugestões a colaborar na resolução de parte dos obstáculos aqui tratados. A primeira delas refere-se à necessidade de refinar a articulação dos projetos de Comunicação e Política com especialidades científicas vizinhas. Em segundo lugar, destaca-se o papel das associações científicas enquanto entidades fundamentais na tarefa de patrocinar o alargamento das fronteiras da pesquisa na área.

\section{CARÊNCIA DE ARTICULAÇÃO COM ESPECIALIDADES VIZINHAS}

Um problema recorrente na especialidade aqui tratada concerne à resistência em promover a integração da área de Comunicação e Política com estudos de áreas tangentes - é o caso da opção por negligenciar a Economia Política da Comunicação e as políticas públicas no setor (Rothberg, Napolitano \& Stroppa, 2016).

O livro da Hallin e Mancini (2004) representa uma referência emblemática ao associar, de um lado, uma discussão ligada à realidade do mercado de comunicação em diferentes países e, de outro, as estratégias de comunicação política empregadas por atores diversos. Outro estudioso importante que defende a aproximação entre as competências da Economia Política e da Comunicação e Política é Papathanassopoulos (2015, p. 770), ao afirmar que:

... de fato, existe uma relação crítica entre, de um lado, as políticas da comunicação midiática e, de outro, a comunicação política. Esses diferentes processos de exercício do poder se alimentam uns dos outros e, desde que haja equilíbrio de poder, eles se limitam mutuamente em benefício do interesse público.

Estreitar o diálogo com a literatura da Economia Política da Comunicação (como o fazem Lattman-Weltman e Chagas (2016), por exemplo) abriria a oportunidade de inserir em nossa agenda temas como o poder das empresas de telecomunicações sobre os novos modelos de negócios de instituições do campo midiático - o que afeta desde o financiamento de campanhas eleitorais até a atividade jornalística. Um desafio relevante, assim, encontra-se na rejeição à permanência em zonas de conforto epistemológico.

$\mathrm{Na}$ mesma trilha da resistência percebida nos estudos de Comunicação e Política em se aproximarem de teorias e metodologias pouco familiares pode ser incluída a análise de conteúdos visuais - o que, especula-se, pode ser resultado da falta de trânsito junto às Teorias da Imagem. Os poucos movimentos nessa direção se associam à análise do discurso ou partem do legado da Semiótica para propor análises contestáveis da relação entre texto e imagem (quando não o fazem de forma fragmentada, separando os dois tipos de conteúdo - texto e imagem - em artigos diferentes e, assim, comprometendo a compreensão integral da mensagem). Há de se fomentar essa aproximação, bem como propiciar uma maior integração entre metodologias que visam abarcar um mesmo conjunto de objetos. 


\section{O PAPEL DAS ASSOCIAÇões CIENTÍfICAS E dOS PERIÓdICOS NA AGENDA DE PESQUISA}

Não pode ser desconsiderado o papel de associações e de eventos da área de Comunicação e Política no que concerne ao incentivo a debates epistemológicos. São fundamentais, por exemplo, mesas redondas dispostas a dar voz, especificamente, a editores de periódicos interessados na interface aqui discutida. Em tais oportunidades, os autores poderiam conhecer mais de perto não somente as características desejáveis com as quais deveriam contar os artigos submetidos (ou compreender as falhas mais recorrentes apontadas nas submissões recusadas), como também verificar o grau de transparência dos processos de avaliação (o que contribui para profissionalizar o campo). Essas ocasiões serviriam, ainda, para que os editores, justamente por terem contato com o que de mais recente vem sendo produzido pelos investigadores, identificassem publicamente quais agendas carecem de maior investimento.

Aproveitar os encontros científicos para promover esclarecimentos, cooperações e embates sobre ciência de boa qualidade abriria a oportunidade para que temas até agora pouco trabalhados - mas, nem por isso, desimportantes - ganhassem condição para serem debatidos em profundidade. Dentre os assuntos ainda pouco explorados (e que poderiam ser alvo de dossiês, por exemplo), estão: a utilização cada vez mais frequente de militantes para "terceirizar" a crítica a adversários por meio de perfis em redes sociais digitais; as particularidades do consumo de informações políticas simultaneamente em múltiplas telas; o aperfeiçoamento dos processos de transparência pública em organizações do estado; a comparação entre as dimensões opinativa e noticiosa dos jornais com o intuito de perceber se (e em que medida) há viés.

Delineado o que o argumento tinha de fundamental a apresentar, é chegado o momento de elaborar duas ponderações finais.

Em primeiro lugar, pergunta-se: Até que ponto os problemas verificados em parte das pesquisas conduzidas no Brasil se repetem em outras democracias? Se é verdade que as diretrizes institucionais (seja do sistema político, seja do sistema da mídia) ou as características da cultura política nacional influenciam os interesses de investigação mais recorrentes, registre-se que os problemas anteriormente apontados não são exclusividade da literatura brasileira em Comunicação e Política. Assim, mesmo que impliquem variações de tom, as críticas ao ramo dos Estudos de Mídia aqui posto em tela se repetem em outros contextos sociais, políticos e intelectuais (Blumler, 2016).

Partindo de tal constatação, Kaid e Strömbäck (2008) apelam para a necessidade de criar parâmetros de mensuração a serem utilizados por pesquisadores interessados em comparar casos oriundos de diferentes países. Esser e colegas, por sua vez, apontam as dificuldades ocasionadas por imprecisões conceituais e refletem sobre como isso reverbera na operacionalização de variáveis comparativas:

... apesar de todo o progresso, a pesquisa sobre jornalismo político enfrenta sérios desafios relacionados à falta de clareza conceitual, bem como demonstra uma comparabilidade insuficiente entre os estudos e o acúmulo de conhecimento. (...) Embora muitos estudiosos utilizem conceitos 
teóricos similares, as definições das categorias e, em particular, as opera-

cionalizações diferem frequentemente. (Esser et al., 2011, p. 140)

Tais reflexões comprovam que o problema delineado ao longo deste artigo existe, de fato, e que ele não se limita à produção brasileira. Nesse sentido, a preocupação essencial, aqui, é provocar o debate a fim de saber quão atentos estão os pesquisadores brasileiros a tais problemas e se estão dispostos a desafiá-los.

Por último, é nítido que, ao longo dos últimos dez anos, o perfil do material produzido por investigadores da área de Comunicação e Política tem se aperfeiçoado - principalmente por conta das maiores exigências dos processos de avaliação da pós-graduação no Brasil. Isso, porém, não nos impede de apontar que persistem barreiras para que se verifique um acúmulo consistente de metodologias, bem como para que se amplie a inserção de nossas investigações em âmbito internacional - um estorvo persistente e que vai além de eventuais barreiras linguísticas.

\section{REFERÊNCIAS BIBLIOGRÁFICAS}

Albuquerque, A. (1999). Aqui você vê a verdade na tevê: A propaganda política na televisão. Niterói: Universidade Federal Fluminense.

Albuquerque, A. (2013). Media/politics connections. Media, Culture Q Society, 35(6), 742-758. doi: $10.1177 / 0163443713491302$

Aldé, A., Chagas, V. \& Santos, J. G. B. (2013). Teses e dissertações defendidas no Brasil (1992-2012): um mapa da pesquisa em comunicação e política. Revista Compolítica, 3(2), 7-43. doi: 10.21878/ compolitica.2013.3.2.43

Andrade, D. S. (2014). A comunicação governamental da presidente Dilma Rousseff: uma análise de conteúdo do portal da Presidência da República. Comunicação e Sociedade, 26, 191-206. doi: 10.17231/ comsoc.26(2014).2033

ANPOCS, Associação Nacional dos Programas de Pós-Graduação em Ciências Sociais. (2018). Encontros Anteriores. São Paulo: ANPOCS. Retirado de http://www.anpocs.com/index.php/encontros/ encontros-anteriores

Azevedo, F. (2010). A imprensa brasileira e o PT: um balanço das coberturas das eleições presidenciais (19892006). Revista ECO-Pós, $12(3)$, 48-65.

Barakso, M., Sabet, D. \& Schaffner, B. (2013). Understanding political science research methods. Londres: Routledge. doi. 10.4324/9780203801253

Bardin, L. (2007). Análise de conteúdo. Lisboa: Edições 70.

Biroli, F. (2013). Limites da política e esvaziamento dos conflitos: o jornalismo como gestor de consensos. Revista Estudos Políticos, 6, 144-161.

Blumler, J. (2016). Political communication. In G. Mazzoleni, K. Barnhurst, K. Ikeda, H. Wessler \& R. Maia (Eds.), The international encyclopedia of political communication (pp. 1-9). Londres: Wiley-Blackwell. doi: 10.1002/9781118541555.wbiepc213

Bohman, J. (1996). Public deliberation: pluralism, complexity, and democracy. Cambridge: MIT press. doi: $10.5860 /$ choice.34-5341 
Bresser-Pereira, L. (2017). The political construction of Brazil: society, economy, and state since independence. Boulder: Lynne Rienner Publishers.

Campos, L. (2014). A identificação de enquadramentos através da análise de correspondências. Opinião Pública, 20(3), 377-406. doi: 10.1590/1807-01912014203377

Canavilhas, J. (2010). Do gatekeeping ao gatewatcher: o papel das redes sociais no ecossistema mediático. In Nuevos Medios, Nueva Comunicación - Livro de atas do II Congreso Internacional Comunicación 3.0 (pp. 1-12). Salamanca: Universidad de Salamanca. Retirado de http://campus.usal. es/ comunicacion3puntoo/comunicaciones/061.pdf

CAPES, Coordenação de Aperfeiçoamento de Pessoal de Nível Superior. (2017). Relatório da Avaliação Quadrienal 2017: Comunicação e Informação. Brasília, CAPES. Retirado de http://capes.gov.br/images/ stories/download/avaliacao/relatorios-finais-quadrienal-2017/20122017-Comunicacao-quadrienal.pdf

Carvalho, R. (1999). Transição democrática brasileira e padrão midiático publicitário da política. Campinas: Pontes.

Cervi, E. (2009). Métodos quantitativos nas ciências sociais: uma abordagem alternativa ao fetichismo dos números e ao debate com qualitativistas. In J. Bourguignon (Eds.), Pesquisa Social (pp. 125-143). Ponta Grossa: Toda Palavra.

Charaudeau, P. (2006). Discurso político. São Paulo: Contexto.

Chaui, M. (2006). Simulacro e poder: uma análise da mídia. São Paulo: Fundação Perseu Abramo.

Citelli, A., Berger, C., Baccega, M., Lopes, M. \& França, V. (Eds.). (2014). Dicionário de comunicação: Escolas, teorias e autores. São Paulo: Contexto.

Compolítica, Associação Brasileira de Pesquisadores em Comunicação e Política. (2018). Diretório de Teses e Dissertações. Rio de Janeiro: Compolítica. Retirado de http://compolitica.org/diretorio/index.php/ diretorio/catalog

Compós, Associação Nacional dos Programas de Pós-graduação em Comunicação. (2018). Anais. Brasília: Compós. Retirado de http://www.compos.org.br/anais_encontros.php

Correia, J. C. (2005). Recensão do livro Comunicação e Política: conceitos e abordagens, de A. A. C. Rubim. Media Q Jornalismo, 7, 137-147.

Duarte, J. (Ed.) (2012). Comunicação pública: estado, mercado, sociedade e interesse público. São Paulo: Atlas.

Editorial: O mal a evitar (2010, 26 de setembro). O Estado de São Paulo, p. A3.

Eilders, C. (1999). Synchronization of issue agendas in news and editorials of the prestige press in Germany. The International Journal of Communications Research, 24(3), 301-328. doi: 10.1515/comm.1999.24.3.301

Elster, J. (Ed.) (1998). Deliberative democracy. Cambridge: Cambridge University Press. doi: 10.1017/ cbog781139175005

Entman, R. (1993). Framing: toward a clarifcation of a fractured paradigm. Journal of Communication, 43(4), 51-58. doi: 10.1111/j.1460-2466.1993.tbo1304.x

Esser, F., Strömbäck, J. \& De Vreese, C. (2012). Reviewing key concepts in research on political news journalism. Journalism, 13(2), 139-143. doi: 10.1177/1464884911427795

Fairclough, N. (2001). Discurso e mudança social. Brasília: Universidade de Brasília.

Fausto Neto, A. (2004) Discurso político e mídia. In A. A. Rubin, (Ed.), Comunicação e Política: conceitos e abordagens (pp. 105-125). Salvador: Edufba. 
Fausto Neto, A. (2008). Notas sobre as estratégias de celebração e consagração do jornalismo. Estudos em Jornalismo e Mídia, 5, 17-29. doi: /10.5007/1984-6924.2008v5n1p109

Fernandes, C. M. \& Correia, G. C. (2014). Mídia jornalística como instrumento de ação política no Golpe Militar de 1964. Estudos em Jornalismo e Mídia, 11(1), 77-88.

Figueiredo, C. D. \& Mendes, A. R. S. (2015). Roteiros para dispositivos de mídias móveis: tela, tempo e trânsito como elementos contingentes. Revista GEMInIS, 6(2), 165-182, 2015.

Figueiredo, M. (2008). A decisão do voto. Belo Horizonte: Editora UFMG.

Foucault, M. (1979). Microfísica do poder. Rio de Janeiro: Graal.

Gamson, W. \& Modigliani, A. (1989). Media discourse and public opinion on nuclear power. American Journal of Sociology, 95(1), 1-37. doi: 10.1086/229213

Gamson, W. (1992). Talking politics. Cambridge: Cambridge University Press.

Giacomini Filho, G. (2013). Publicidade: possibilidades para um receptor interativo. In A. Pessoni \& P. F. Perazzo (Eds.), Neorreceptor no fluxo da comunicação (pp. 15-32). Porto Alegre: EdiPUCRS.

Goffman, E. (1986). Frame analysis: an essay on the organization of experience. Boston: Northeastern University Press.

Gomes, A. L. \& Torres, J. V. C. (2017). Nos labirintos do discurso: agendamento e procedimentos de exclusão nos títulos da Folha, Globo e Estadão. Comunicação Q Inovação, 18(36), 68-78.

Gomes, W. \& Maia, R. (2008). Comunicação e democracia: problemas e perspectivas. São Paulo: Paulus.

Gomes, W. \& Moreira, S. V. (2000). O estado da arte dos cursos brasileiros de pós-graduação em Comunicação (entrevista). Revista Brasileira de Ciências da Comunicação, 23(2), 121-136.

Gomes, W. (2003). O estranho caso de certos discursos epistemológicos que visitam a área de Comunicação. In M. Lopes (Ed.) ,Epistemologia da Comunicação (pp. 313-330). São Paulo: Loyola.

Gomes, W. (2004). Transformações da política na era da comunicação de massa. São Paulo: Paulus.

Grijó, W. P. \& Vieira, I. G. (2017) Visibilidade comunicativa na Internet: uma análise da fan page de Marcelo Freixo. Comunicação Q Informação, 20(3), 64-83.

Guareschi, P. (1994). Comunicação e poder: presença e o papel dos meios de comunicação. São Paulo: Vozes.

Guerra, J. (2014). Transparência editorial. Revista Latinoamericana de Ciencias de la Comunicación, 11, 196-209.

Gutmann, A. \& Thompson, D. (1996). Democracy and disagreement. Cambridge: Harvard University Press.

Habermas, J. (1996) Between facts and norms: Contributions to a discourse theory of law and democracy. Cambridge: Polity Press.

Hallin, D. \& Mancini, P. (2004). Comparing media systems. Cambridge: Cambridge University Press. doi: $10.1017 /$ cbog780511790867

Hartley, J. (2015). Narrative, political. In G. Mazzoleni; K. Barnhurst; K. Ikeda; H. Wessler \& R. Maia (Eds.), The international encyclopedia of political communication (pp. 849-857). Londres: Wiley-Blackwell. doi: 10.1002/9781118541555.wbiepc137

Kaid, L. L. \& Strömbäck, J. (2008). Election news coverage around the world. In J. Strömbäck \& L. L. Kaid (Eds.), The handbook of election news coverage around the world (pp. 421-431). Nova lorque: Routledge. doi: $10.4324 / 9780203887172$ 
King, G. (2006). Publication, publication. Political Science QT Politics, 39(1), 119-125. doi: 10.1017/ s1049096506o6o252

Lattman-Weltman, F. \& Chagas, V. (2016). Mercado futuro: a economia política da (re)partidarização da imprensa no Brasil. Dados, 59, 323-356. doi: 10.1590/00115258201679

Liedtke, P. F. (2008). Governando com a mídia: os presidentes e o uso político dos meios de comunicação de massa. Comunicação Q Inovação, 9(16), 32-41.

Lima, V. A. (1997). Políticas regionais de comunicação: novos atores, velhos problemas. In I. Lopes \& J. Marques de Melo (Eds.), Políticas Regionais de Comunicação: Os Desafios do Mercosul (pp. 133-143). Londrina: Intercom.

Lippman, W. (1922/2008). Opinião pública. Petrópolis: Vozes.

Maia, R. (2006). Mídia e vida pública. In R. Maia \& M. Castro (Eds.), Mídia, esfera pública e identidades coletivas (pp. 11-45). Belo Horizonte: Editora UFMG.

Maia, R. (2012). Deliberation, the media and political talk. Nova lorque: Hampton Press.

Marques, F. P. J. \& Carneiro, A. (2018). Corações, mentes e estratégias: A relação entre "marqueteiros" e políticos durante as eleições de 2012 em Fortaleza. Revista de Sociologia e Política, 26(65), 105-131. doi: $10.1590 / 1678-987317266507$

Marques, F. P. J. (2006). Debates políticos na internet: a perspectiva da conversação civil. Opinião Pública, 12(1), 164-187. doi: 10.1590/S0104-62762006000100007

Marques, F. P. J., Silva, F. W. \& Matos, N. (2012). Estratégias de comunicação política online: uma análise do perfil de José Serra no Twitter//Political campaigns and online strategies: the case of the 2010 Brazilian elections. Contemporanea - Revista de Comunicação e Cultura, 9(3), 344-369.

Marques, F. P. J., Miola, E., Mitozo, I. \& Mont'Alverne, C. (2017). Um estudo comparativo entre as agendas políticas dos jornais Folha de S. Paulo e O Estado de S. Paulo nas seções opinativa e informativa. $41^{\circ}$ Encontro Anual da ANPOCS - Livro de atas do $41^{\circ}$ Encontro Anual da Associação Nacional de PósGraduação e Pesquisa em Ciências Sociais (pp. 1-26), Caxambu: ANPOCS.

Marques, F. P. J., Vimieiro, A. C. S. C., Vieira, A. C. R. \& Melo, S. B. C. (2009). O fórum na tela: eleições, debates televisivos e deliberação mediada. Contemporanea, 7(1), 1-28.

Marta X Maluf (2000, 15 de outubro). Folha de S. Paulo, p. A2.

Matos, H. (1994). Mídia, eleições e democracia. São Paulo: Scritta.

Matos, H. (Ed.). (2012). Comunicação pública: interlocuções, interlocutores e perspectivas. São Paulo: ECA/USP.

McCombs, M. E. \& Shaw, D. (1972). The agenda-setting function of mass media. Public Opinion Quarterly, 36(2), 176-187. doi: 10.1086/267990

McKnight, D. (2010). A change in the climate? The journalism of opinion at News Corporation. Journalism, 11(6), 693-706. doi: 10.1177/1464884910379704

Melo, J. M. de (1999). A produção acadêmica brasileira em comunicação. Revista Famecos, 6(11), 7-26. doi: 10.15448/1980-3729.1999.11.3048

Miguel, L. \& Biroli, F. (2010). Mídia, representação e democracia. São Paulo: Hucitec.

Miguel, L. (2015). Quanto vale uma valência? Revista Brasileira de Ciência Política, 17, 165-178. doi: $10.1590 / 0103-335220151706$ 
Miguel, L. F. \& Biroli, F. (Eds.) (2010). Mídia, representação e democracia. São Paulo: Hucitec.

Miola, E. (2009). Deliberação online em ambientes institucionais: um estudo do fórum de discussão do portal da câmara dos deputados. Contemporanea, 7(2), 1-24.

Moisés, J. (2008). Cultura política, instituições e democracia. Revista Brasileira de Ciências Sociais, 23(66), 1143. doi: $10.1590 /$ so102-69092008000100002

Moragas, M. (1981). Teorías de la comunicación. Barcelona: Gustavo Gili.

Mundim, P. (2014). Cobertura da imprensa e eleições presidenciais de 2006. Revista Brasileira de Ciências Sociais, 29, 91-107. doi: 10.1590/s0102-69092014000300007

Orlandi, E. (2007). Análise de discurso. Campinas: Pontes.

Ortiz, R. (1990). Notas sobre as ciências sociais no Brasil. Novos Estudos, 27, 163-175.

Papathanassopoulos, S. (2015). Media policy. In G. Mazzoleni, K. Barnhurst, K. Ikeda, H. Wessler \& R. Maia (Eds.), The international encyclopedia of political communication (pp. 1-9). Londres: Wiley-Blackwell. doi: $10.1002 / 9781118541555 . w b i e p c 094$

Partido dos Trabalhadores. (2015). Globo: 50 anos de manipulação. Brasília. Retirado de http://www.pt.org.br/ globo-5o-anos-de-manipulacao/

Paulino, F. P., Guazina, L. \& Oliveira, M. (2016). Serviço público de média e comunicação pública: conceito, contextos e experiências. Comunicação e Sociedade, 30, 55-70. doi: 10.17231/comsoc.30(2016).2485

Pêcheux, M. (1988). Semântica e discurso. São Paulo: Unicamp.

Peruzzo, C. M. K. (2003). Mídia local e suas interfaces com a mídia comunitária. In M. Ledo; X. López \& M. Salgueiro (Eds.), Anuário internacional de comunicação lusófona (pp. 141-162). São Paulo: LUSOCOM.

Recuero, R., Zago, G. \& Bastos, M. T. (2014) O discurso dos\# ProtestosBR: análise de conteúdo do Twitter. Galáxia, 28, 199-216. doi: 10.1590/1982-25542014217911

Rede Globo. (2018). Debate collor x Lula. Retirado de http://memoriaglobo.globo.com/erros/debate-collor-xlula.htm

Rothberg, D., Napolitano, C. J. \& Stroppa, T. (2016). Direito, sociedade e comunicação: um exame do anteprojeto de lei da mídia democrática no Brasil. Comunicação a Informação, 30, 87-102. doi: 10.17231/ comsoc.30(2016).2487

Rubim, A. (Ed.) (2004). Comunicação e política. Salvador, Edufba.

Sampaio, A. (2010). Um novo cenário na TV aberta brasileira. Encontro de estudos multidisciplinares em cultura - Livro de Atas do VI ENECULT (pp. 1-15). Salvador: FACOM/UFBA.

Santos, J. G. B., Aldé, A. \& Schwambach, A. C. F. (2016). Panorama das teses e dissertações brasileiras envolvendo internet e política de 1995 a 2014. 40 Encontro anual da ANPOCS - Livro de atas do $40^{\circ}$ Encontro anual da Associação Nacional de Pós-Graduação e Pesquisa em Ciências Sociais (pp. 1-27), Águas de Lindóia: ANPOCS.

Seridorio, D. F. \& Luvizotto, C. K. (2017). Internet como espaço de deliberação e participação política. Comunicação Q Sociedade, 39(3), 79-110.

Silva, G. (2009). De que campo do jornalismo estamos falando? Matrizes, 3(1), 197-212.

Sokal, A. \& Bricmont, J. (2010). Imposturas intelectuais. Rio de Janeiro: Record. 
Sousa, C. H. P. \& Marques, F. P. J. A. (2015). Wikipédia, democracia e eleições municipais em São Paulo: um estudo sobre as edições de verbetes durante a campanha eleitoral de 2012. RECIIS. Revista Eletrônica de Comunicação, Informação Q Inovação em Saúde, 9(2), 1-25. doi: 10.29397/reciis.vgi2.940

Vallone, R., Ross, L. \& Lepper, M. (1985). The hostile media phenomenon. Journal of Personality and Social Psychology, 49, 577-585. doi: 10.1037//0022-3514.49.3.577

Van Dijk, T. A. (2008). Discurso e poder. São Paulo: Contexto.

Vimieiro, A. \& Maia, R. (2011). Análise indireta de enquadramentos da mídia. Revista Famecos, 18(1), $235-252$. doi: 10.15448/1980-3729.2011.1.8810

Weber, M. H. (1990). Pedagogias de despolitização e desqualificação da política brasileira (as telenovelas da Globo nas eleições de 1989). Comunicação Q Política, 1, 67-84.

Weber, M., Coelho, M. \& Locatelli, C. (Eds.) (2017). Comunicação pública e política Florianópolis: Insular.

\section{Agradecimentos}

Os autores agradecem a Camila Mont'Alverne, Isabele Mitozo e Paulo Ferracioli pela leitura e revisão do texto. Isabele Mitozo, ademais, ficou responsável pela tradução do artigo para a versão em inglês. Também merecem destaque a CAPES (Auxílio Prêmio de Teses) e o CNPq (bolsas de iniciação científica e de produtividade em pesquisa; Edital Ciências Humanas e Sociais, processo 444493/2015-8).

\section{NOTAS BIOGRÁFICAS}

Francisco Paulo Jamil Marques é Doutor em Comunicação e Cultura Contemporâneas (UFBA, 2008). Professor e Pesquisador da Universidade Federal do Paraná. Bolsista de Produtividade em Pesquisa do CNPq. Áreas de investigação: Comunicação Política; Opinião Pública; Jornalismo; Democracia Digital; Mídia e Eleições.

E-mail: marquesjamil@gmail.com

Morada: Avenida Silva Jardim, 368, apto. 1602

Rebouças, Curitiba, Paraná, Brasil

CEP: 80230-000

Edna Miola é Doutora em Comunicação Social (UFMG, 2012). Professora e Pesquisadora da Universidade Tecnológica Federal do Paraná. Áreas de investigação: Comunicação Política; Comunicação Pública; Opinião Pública.

E-mail: ednamiola@gmail.com

Morada: Avenida Silva Jardim, 368, apto. 1602

Rebouças, Curitiba, Paraná, Brasil

CEP: 80230-000

* Submetido: 30.11 .2017

* Aceite: 15.03 .2018 